\title{
Contribuições da psicologia da saúde-hospitalar na atenção ao paciente cirúrgico ${ }^{1}$
}

\author{
Ricardo Werner Sebastiani² ${ }^{2}$ Eulália Maria Chaves Maia $^{3}$
}

\begin{abstract}
Sebastiani RW, Maia EMC. Contribuições da psicologia da saúde - hospitalar na atenção ao paciente cirúrgico. Acta Cir Bras [serial on line] Available from: URL: htt://www.scielo.br/acb.

RESUMO - Objetivo: O presente artigo discute algumas contribuições da Psicologia Hospitalar à atenção ao paciente cirúrgico, utilizando como pressuposto as propostas de intervenção interdisciplinar em saúde dentro do paradigma biopsicossocial. Métodos e resultados: Apresenta aspectos relacionados à relação cirurgião-equipe de saúde-paciente e elenca alguns processos de respostas psicológicas e psicopatológicas do paciente frente ao trinômio doença-internação-tratamento no período que vai do diagnóstico e indicação cirúrgica até a fase de pós-operatório tardio e reabilitação do paciente. Conclusão: o psicólogo instrumentalizar-se adequadamente para conquistar, pelo seu conhecimento, pelo valor de seu trabalho e pela sua dedicação, seu espaço dentro das equipes cirúrgicas.
\end{abstract}

DESCRITORES: Psicologia Hospitalar, Relação cirurgião-paciente, equipe interdisciplinar, Atenção psicológica ao paciente cirúrgico.

\section{Introdução}

Os Modelos Biomédico e Biopsicossocial e suas influências na construção da Psicologia Científica e Aplicada; do Séc. XIX ao XXI

A Psicologia desenvolve sua história, enquanto Ciência e Profissão notadamente a partir da segunda metade do século XIX, a se considerar como marco indicativo de sua estruturação científica os trabalhos de Wundt publicados pela Universidade de Liepezieg em $1857^{1}$

Os primórdios dessa ciência e, por conseguinte, da profissão de psicólogo, encontram-se associados, por aquilo que poderia denominar-se de o "zeith geist" que marcou a evolução do pensamento científico da última metade do século XIX até meados do século XX, influenciado de maneira contundente pela visão cartesiano-positivista que se impõe paradigmaticamente a todos os segmentos das ciências, inclusive às escolas psicológicas da época e, por conseguinte, todos os processos e procedimentos que se desenvolveram a partir das teorias preconizadas por estas.

Foucault ${ }^{2}$ em sua obra "O Nascimento da Clínica" demonstra de forma clara, como as Ciências da Saúde, e em particular a Psicologia, se sentem influenciadas por esses modelos, e como a construção do modelo clinicalista, se desenvolve à sombra dos pressupostos mecanicistas que determinaram a estruturação e hegemonia do modelo biomédico. Embora historicamente se tenha uma divisão daquilo que Ekstermann ${ }^{3}$ identifica como modelos Nomotético e Idiográfico, associando o primeiro ao Setting Psicanalítico a partir dos modelos filosóficos da escola médica Hipocrática, e o segundo aos modelos Kraepelinianos derivando do modelo da Escola de Galeno, criando-se, portanto, linhas de pensamento que priorizavam a visão do homem como ente singular ou, no caso da visão Kraepeliniana, do homem como espécie, fica bastante evidente, no transcurso dos primeiros cem anos de história da psicologia científica, a forte influência da visão cindida do processo corpo-mente, fator que irá reforçar a construção de práticas voltadas ao "indivíduo psíquico" ou ao "indivíduo biológico", na maior parte das vezes desconectadas tanto em seu pensar quanto em seu fazer, uma da outra.

Conforme salienta Barra , "A concepção dualista de que mente e corpo funcionam separadamente, de forma independente, estaria representada em sua máxima expressão nas idéias do filósofo René Descartes, o qual defende a idéia de que a alma ou a mente eram uma unidade distinta incapaz de afetar de uma maneira direta a matéria física ou os processos somáticos. Esse Dualismo Cartesiano mente e corpo proporcionou a base filosófica do novo campo independente da medicina, alheandoa do enfoque holístico que enfatizava a interdependência mente-corpo, e conduziu-a ao enfoque fisiopatológico mecanicista que tem caracterizado essa disciplina até muito recentemente".

Estes fatores influenciam, até hoje, as teorias e as estratégias que vão determinar a prática do psicólogo, começando pelos modelos teóricos que são apresentados aos estudantes, ain-

1. Trabalho realizado durante o Programa de Pós-Graduação em Ciências da Saúde da Universidade Federal do Rio Grande do Norte.

2. Doutorando em Ciências da Saúde pela Universidade Federal do Rio Grande do Norte - programa de Pós-Graduação em Ciências da Saúde, Mestre em Saúde Pública pela Universidade de S. Paulo, Coordenador dos Serviços de Psicologia Hospitalar dos Hospitais do Servidor Público Municipal de S. Paulo e Brigadeiro - SUS - S. Paulo.

3. Professora Doutora do Departamento de Psicologia da Universidade Federal do Rio Grande do Norte, Coordenadora da Base de Pesquisas GEPPS Grupo de Estudos e Pesquisas em Psicologia e Saúde e do Curso de Especialização em Psicologia da Saúde do Programa de Pós-Graduação em Ciências da Saúde da UFRN. 
da durante a fase inicial de sua formação profissional. A própria evolução que as Ciências da Saúde experimentou, (e enfatize-se aqui, graças em grande parte ao rigor que o modelo científico vigente sê-lhe impôs) gerou um significativo avanço nos conhecimentos e na perspectiva de compreensão do fenômeno humano e da relação saúde-enfermidade, não obstante, contribuiu para hierarquizar, burocratizar e cindir o homem, começando pela divisão corpo-mente, e evoluindo de forma impressionante para a própria divisão órgão-corpo e cérebro-mente. Os modelos de estudos do fenômeno humano passam a valorizar cada vez mais, uma visão atomista/reducionista, que, se por um lado favorece o aprofundamento do conhecimento, por outro dificulta, cada vez mais, ao profissional da saúde, compreender o homem numa dimensão multifatorial e multicausal na sua relação evolutiva com os processos de vida e existência, dificultando assim, a visão global do indivíduo, e por conseqüência, a forma de se compreender e intervir por sobre o binômio saúde-doença.

De fato, o movimento científico que se inicia de forma específica no campo das Ciências da Saúde (médicas) tem um marco importante na sua doutrina mecanicista-biologicista em 1910 através do Relatório Flexener, que preconiza um modelo hegemônico no campo da saúde vigente até muito recentemente. $\mathrm{O}$ ponto central desse ideário é o curativismo o mecanicismo e a noção de unicausalidade ${ }^{6}$. Como elemento de referência o curativismo reforça a idéia (fortemente incidente até os anos 70) de que a saúde é a ausência de doença em um indivíduo, levando assim, as práticas em saúde, e em particular a formação e a prática médica, à busca da cura dos indivíduos que manifestam algum tipo de doença, identificando esse tipo de ação como o escopo principal (único) da função do médico e dos profissionais de saúde.

Pode-se afirmar que a gradativa perda da visão global do indivíduo, e em particular do indivíduo enfermo, passou a criar novos problemas dentro das práticas de atenção à saúde, e a contribuir para que esta mesma (falta de visão) passasse a representar mais um fator de agravo à saúde das pessoas. Nesse sentido é interessante, por exemplo, considerar-se o quanto se tem dado de importância ao tema "Humanização da Saúde", sendo esse inclusive uma das diretrizes das políticas e programas do Comitê Técnico do Programa Nacional de Humanização da Assistência Hospitalar do Brasil ${ }^{7}$, mas a encarar-se objetivamente o próprio tema ver-se-á o absurdo de se falar em "humanização" de um aspecto que deveria ser inerente a si mesmo (a saúde do humano humanizada).

Estes paradigmas começam a experimentar novas influências a partir da segunda metade do século XX, quando se iniciam processos mais sistematizados de críticas e questionamentos às verdades que o modelo científico biomédico propõe, geradas dialeticamente, pelos seus próprios avanços, ressalte-se aqui as importantes contribuições do movimento psicossomático ${ }_{8,9}$. Pode-se constatar, assim, que a construção de uma nova ordem paradigmática no campo das Ciências da Saúde começa a nascer por essa época, que teve na estruturação da Organização Mundial da Saúde, em 1945, importante precursor institucional, e evolui aos dias de hoje, com a construção de um novo modelo plenamente em curso.

As contribuições de Kurt Lewin para a Psicologia Social Aplicada (ao longo dos anos 40), assim como a importante contribuição da Medicina Psicossomática à mesma época, representaram antecedentes muito significativos para a Psicologia da Saúde.

Observa-se, portanto uma clara disputa dentro do campo das Ciências da Saúde entre a defesa do status-cuo do modelo biomédico (vigente durante os últimos 150 anos) e a nova propositura de um modelo biopsicossocial, que traz como vertente paradigmática o resgate da visão integral do indivíduo, e a compreensão do binômio saúde-doença, como um fenômeno multicausal e interdependente na e da relação indivíduo - mundo.

Sendo assim, pode-se considerar que, nascendo por volta dos anos 50 e mais intensamente a partir dos anos 70, movimentos muito importantes firmam de maneira definitiva a posição de confronto que esse novo paradigma.

Com base nesse paradigma, Foratinni ${ }^{10}$ propõe uma visão integral da saúde e compreensão do fenômeno saúde-doença como eventos multifatoriais, que são relativamente recentes no universo das Ciências da Saúde, e que um importante movimento de redefinição das ações de saúde vem sendo proposto há mais de três décadas.

Ao somar-se a essas novas vozes o que propõe a leitura de Lalonde $^{11}$ que questiona o papel exclusivo da medicina na resolução dos problemas de saúde e influencia de forma decisiva o início de uma nova era de interesse político e social pela saúde, ver-se-á que o novo paradigma tem uma importância fundamental no que se refere à presença e participação da Sociologia, da Psicologia, da Pedagogia entre outras ciências nas diferentes propostas de atenção à saúde da população, posto que os elementos participantes do processo de instalação das doenças mencionados por Susser "enfermidade" e "anormalidade" são notoriamente de cunho psicossocial.

Estas idéias tomaram corpo e forma a partir desses autores, com ênfase às leituras de Lalonde que considerava que a ação de quatro fatores interligados seriam os determinantes da doença, ampliando assim o conceito de saúde. Eram eles: as características biofísicas da pessoa; poluição e agravos ambientais; estilo de vida; e inadequação e incompetência dos serviços de saúde ${ }^{12}$.

Ao longo dos anos 80 e 90, a OMS patrocina cerca de treze conferências mundiais e regionais que passam a construir e propor novas diretrizes para os programas e políticas de atenção à saúde ${ }^{13}$, onde fatores como: comportamento, estilo de vida, meio ambiente, políticas públicas, violência, economia, entre outros, passam a compor o macro campo de estudos das Ciências da Saúde, não mais focados exclusivamente no binômio saúde-doença e no pressuposto curativista, mas que 
consideram o processo Saúde e Desenvolvimento Humano como ponto de partida para a formulação das políticas de saúde e propõe a reformulação dos serviços de atenção à saúde, desde a formação dos profissionais envolvidos, até a ampla reforma dos modelos e reorganização dos recursos materiais e humanos, sob a égide da interdisciplinariedade, intersetorialidade embasadas numa leitura biopsicossocioambiental.

Por tanto, cada dia mais, a valorização de intervenções primárias, secundárias ou terciárias em saúde, pressupõe a necessidade de se compreender e intervir sobre estes contextos de indivíduo e/ou grupos, expostos às diferentes moléstias ou outras condições de agravo à saúde a partir de uma leitura global. A Psicologia da Saúde vem sendo solicitada a dar sua parcela de contribuição à abordagem destes problemas, e é imperativo que esse campo possa ser capaz de responder a esses pedidos, e que a Psicologia se organize, cada vez mais, para que a inserção sócio-sanitária desse saber/fazer seja mais eficiente e reconhecida.

\section{O perfil do cirurgião e sua relação com o paciente}

Como o médico atual pode ser considerado "descendente" dos feiticeiros e curandeiros pelo imaginário de muitos pacientes, para compreender seu papel é necessário recordar que a doença pode, em diversas culturas, ser percebida como uma punição, que resulta na introdução do corpo do doente de um elemento maléfico e estranho, ou até mesmo a perda de um bom elemento interior.

Frente a esta situação, o médico tem como finalidade extirpar do paciente o mau elemento, ou capturar e reintroduzir o elemento bom. Para executar tal ação, o feiticeiro necessita controlar as forças do bem e do mau, bem como estabelecer um pacto com ambos os representantes. Neste mesmo contexto, o doente esta sujeito a sofrer e até morrer para em seguida ressuscitar e alcançar a cura desejada.

É comum este lado mágico ainda se fazer presente no imaginário de muitos pacientes, pois a simples visita ao médico faz o doente melhorar, e ao identificar a doença pelo profissional, o paciente acredita que o médico irá encarregar-se dela e vencêla, porém é este lado mágico que leva o paciente a enxergar o médico com reserva, prudência e desconfiança. O temor e o respeito perante o médico estão conseqüentemente associados ao homem mau e ao salvador, sendo esta leitura aparentemente paradoxal presente, e não raro determinante, de muitas relações entre o cirurgião e o paciente. Este profissional tem acesso aos segredos da vida, da morte, do corpo e até do sexo.

Em duas pesquisas qualitativas desenvolvidas com pacientes e cirurgiões nos Hospitais do Servidor Público Municipal de S. Paulo e Brigadeiro - S. Paulo, entre 2002 e $2003^{14,15}$, orientadas pelo presente autor, constatou-se importante diferença de leitura e significação do processo cirúrgico e das imagens que os protagonistas (cirurgião e paciente) faziam de si e do outro. As pesquisas apresentavam tanto aos cirurgiões quanto pacientes questões idênticas que versavam sobre a importância da cirurgia, o que cada um entendia como essencial para o êxito da mesma, como cada um via seu papel e imagem no processo cirúrgico e como este via o papel do outro (cirurgião ou paciente) na relação médico-paciente e na cirurgia em si.

Os resultados demonstraram algumas diferenças importantes entre estas leituras, e apontaram para a influência da relação humana cirurgião-paciente em todas as fases do processo cirúrgico - do diagnóstico e indicação da cirurgia até o pósoperatório tardio.

As respostas dos cirurgiões em relação ao que eles acreditam que o paciente espera deles eram racionais e apontavam predominantemente para o conhecimento científico, o domínio técnico, a seriedade e responsabilidade, ao passo que os pacientes elencavam estas características como importantes, mas secundárias, estes esperavam prioritariamente um médico "amigo", sincero, acolhedor, disponível para conversar com eles e ouvi-los.

$\mathrm{Na}$ inversão da questão os pacientes acreditavam que aborreciam os médicos com suas dúvidas e medos, que eram vistos por eles como seres frágeis e desprotegidos e que os médicos não podiam lhes dar mais atenção devido à sobrecarga de responsabilidades e tarefas, ao passo que os cirurgiões julgavam que os pacientes se sentiam seguros, bem informados, frágeis e depressivos e predominantemente com medo do processo cirúrgico. Estas duas últimas leituras dos médicos (aparentemente lógicas) foram desmentidas pelos pacientes quando indagados sobre o que sentiam e esperavam da cirurgia onde as respostas predominantemente indicavam otimismo, fé, e esperança de cura ou melhora em seu quadro atual.

Ficou evidenciada a grande diferença na forma de interpretar o processo cirúrgico e a relação cirurgião-paciente, onde o conjunto de respostas dos pacientes apresentava um eixo mais "emocional/afetivo" enquanto as dos cirurgiões mais "racional/técnica". Chama a atenção o fato de que ambos os atores, embora envolvidos em processo intenso de relacionamento, não tenham sido capazes de efetivamente comunicarem-se uns com os outros.

Este resultado é corroborado por outro conjunto de respostas onde os grupos são indagados sobre "como é a seu ver um paciente (ou médico) ideal":

Os pacientes respondem que o "médico ideal" é aquele amigo, bem humorado, presente, disponível para ouvi-lo e que transmita segurança a eles.

Os cirurgiões acreditam que o paciente espera um médico sério, responsável e com pleno domínio técnico da situação. Na inversão da pergunta os médicos referem que o "paciente ideal" é aquele que obedece às orientações, que se esforça por adequar-se às rotinas hospitalares, e que confie no médico. Ao passo que os pacientes acreditam que o "paciente 
ideal" (para o médico) é aquele que se preocupa com sua saúde, que não "reclama muito", que não importuna o médico com suas dúvidas, embora não seja esta a expectativa que eles (pacientes) têm do médico. Sem dúvida estes resultados apontam para importantes diferenças de leitura da relação e do processo de comunicação entre o cirurgião e o paciente, denotando, entre outros aspectos, que a expectativa de uma relação mais humanizada está presente no discurso do paciente, ao passo que o médico entende que competência técnica e objetividade no trato com o paciente são suficientes para atender às demandas emocionais deste.

Segundo Mello ${ }^{16}$ pode-se tentar estabelecer uma classificação dos cirurgiões, diante dos seus grupos, reações, tendências, inclinações, comportamentos, emoções e traços mais evidentes da sua personalidade:

\section{$O$ verdadeiro cirurgião}

\section{O exibicionista}

\section{O neurótico}

\section{O displicente}

\section{4. $\mathrm{O}$ anatomista}

\section{O inseguro de si próprio}

Essa "tipologia" proposta por Mello auxilia a compreender determinados padrões de comportamento que influenciam não somente a relação com o paciente, mas a própria postura do cirurgião, ou os estereótipos que sub-liminarmente são passados aos acadêmicos, ainda na graduação ou residência, sobre o que é ser cirurgião. Longe de se enquadrar todos os cirurgiões nesta tipologia, acreditamos que ela, somada aos dados das pesquisas acima mencionadas, possam auxiliar não só o cirurgião, mas a equipe de saúde envolvida na atenção ao paciente a redimensionar os critérios de cuidados e mesmo os protocolos de procedimentos em pré, trans e pós-operatório.

As demandas crescentes que hospitais e serviços de saúde vêm sofrendo no Brasil, influência dos profundos contrastes que diariamente sê-nos são impostos, onde, ao mesmo tempo em que dispomos (ou somos cobrados a conhecer) técnicas, recursos terapêuticos e equipamentos de última geração, vemos e somos vítimas de falta de recursos materiais e humanos para dar conta destas demandas. O profissional de saúde, e o cirurgião em particular, sofrem com estas pressões paradoxais que, ao mesmo tempo em que exigem excelência, impõem limites. O domínio do conhecimento nas Ciências da Saúde há muito se perdeu, devido a seu avanço, profundidade e multi-fracionamento, provocando conflitos e dificuldades no exercício das funções técnicas e, sobretudo, na adequada harmonização das equipes interdisciplinares de saúde. Se por um lado o modelo biomédico cobra pleno domínio do conhecimento e, de certa forma, hegemonia total sobre este, o avanço deste mesmo conhecimento impõe as "sub-especialidades" o fracionamento das ações em saúde e conseqüentemente nega a possibilidade dessa hegemonia, ao passo que o modelo biopsicossocial, pressupõe ações integradas e interdisciplinares, mas ainda padecem de amadurecimento enquanto modelo, seja na própria formação dos profissionais de saúde, seja na difícil e rígida estrutura hierárquica que os modelos de gestão (principalmente hospitalares) impõem, ou mesmo determinado pelas dificuldades que os contrastes da iniquiidade geram para uma eficiente atenção às demandas sócio-sanitárias que nossa população exige quando busca um hospital.

Sabemos que as rotinas hospitalares raramente contemplam tempo, espaço, recursos, etc., o cirurgião para que este possa dar conta de tantas exigências e expectativas. No geral, com exceções que confirmam a regra, vemos profissionais que trabalham exaustivamente, sobrecarregados por horas de cirurgias ininterruptas, com pouco tempo e energia de sobra seja para seus estudos e atualizações ou mesmo para sua vida pessoal.

A presença de outros profissionais na equipe, particularmente o psicólogo, somam importante ajuda ao cirurgião, pois a identificação dos medos, dúvidas, expectativas do paciente, assim como a facilitação de uma interlocução mais eficiente entre equipe de saúde-paciente, fazem parte do escopo e da formação técnica deste profissional, da mesma forma, a psicologia da saúde vêm se dedicando a estudar e desenvolver estratégias de cuidados com o cuidador, identificando situações profissionais potencialmente patogênicas, criando programas e estratégias preventivas e terapêuticas que auxiliem no resgate da qualidade de vida, procurando assim contribuir na otimização dos recursos humanos em saúde, mas não descuidando do "humano" destes recursos, partindo de um pré-suposto simples, mas importante que defende a idéia de que "não pode dar-se o que não se tem"...

O Brasil tem sido identificado em várias pesquisas ${ }^{(17 ; 18 ; 19)}$ como um dos pioneiros mundiais na construção de uma nova especialidade em Psicologia, a Psicologia Hospitalar, que agrega os conhecimentos da Ciência Psicologia para aplicá-los às situações especiais que envolvem os processos doença-internação-tratamento permeados por uma delicada e complexa relação determinada pela tríade enfermo-família-equipe de saúde. Não se trata, portanto, de simplesmente se transpor o modelo clássico de trabalho psicológico e psicoterápico desenvolvido no consultório para o hospital, mas do desenvolvimento de teorias e técnicas específicas para a atenção às pessoas hospitalizadas, que em sua grande maioria apresentam demandas psicológicas associadas ao processo doença-internação-tratamento, tanto como processos determinantes quanto como reações que podem agravar o quadro de base destes pacientes, e/ou impor seqüelas dificultando ou mesmo inviabilizando seu processo de recuperação.

Somadas a estas questões, a relação com os processos de morte e morrer, com as perdas irreversíveis impostas pelas doenças, e toda a angústia e sofrimento gerados por tais situações, têm sido também alvo dos trabalhos do Psicólogo Hospitalar. 
Sendo assim, as contribuições que esta especialidade vem trazendo às diversas modalidades de intervenções médicas vêm crescendo, e em Clínica Cirúrgica, vêm ganhando expressivo espaço, sempre na busca da consolidação do modelo biopsicossocial em saúde, a partir de ações interdisciplinares que contemplem a compreensão da pessoa enferma como um todo.

$\mathrm{Na}$ atualidade, vários procedimentos cirúrgicos têm em seus protocolos a previsão de avaliação e acompanhamento psicológico ao enfermo, desde a indicação da cirurgia, até os programas de reabilitação e reintegração sócio-familiar. Destaca-se nesse campo protocolos de cirurgias bariátricas e outras técnicas cirúrgicas para obesidade mórbida, cirurgias plásticas cosméticas e algumas modalidades de reconstrutivas, transplantes (nestes casos tanto no trabalho direto com o transplantado como na atividade conjunta com as equipes de captação).

\section{Atendimento psicológico em clínica cirúrgica}

A cirurgia é uma especialidade da medicina voltada para a cura de doenças, com a atuação do profissional diretamente no local atingido, unindo, cortando ou retirando o que está prejudicado. Sabe-se que esta especialidade é utilizada desde o inicio da civilização sendo aperfeiçoada através da tecnologia.

Apesar do avanço tecnológico das cirurgias e anestesias, o paciente cirúrgico nunca se sente totalmente seguro, pois este procedimento tende a gerar intenso desconforto emocional, onde o indivíduo tem o seu futuro incerto, manifestando sentimentos de impotência, isolamento, medo da morte, da dor, da mutilação, de ficar incapacitado, das mudanças na sua imagem corporal. Assim, diante da necessidade de realizar uma cirurgia, o paciente sente ameaçada a sua integridade física e psicológica.

Acresce-se o fato de que a cirurgia, em si, pode alterar a imagem corporal do paciente levando-o a desenvolver dificuldades de adaptação e produzindo no indivíduo um déficit na relação do sujeito no mundo, e do sujeito-mundo traduzindo-se no plano da motricidade, da percepção e da relação com o outro.

Entende-se então, que nenhum paciente está efetivamente preparado para realizar uma cirurgia, sendo necessário à atuação psicológica neste momento. O psicólogo deve atuar com o objetivo de minimizar a angústia e ansiedade do paciente, favorecendo a expressão dos sentimentos e auxiliando na compreensão da situação vivenciada, proporcionando também, um clima de confiança entre o paciente e equipe de saúde, e facilitando a verbalização das fantasias advindas do processo cirúrgico.

Faz-se necessário também, o psicólogo atuar no sentido de reorganizar o esquema da consciência do paciente no mundo, ou seja, seu novo esquema corporal que foi modificado pela intervenção cirúrgica, pois, cada indivíduo, vivencia de acordo com sua estrutura de personalidade, graus diferenciados de adaptação à nova imagem corporal. É fato que a reconstrução positiva desta nova imagem é necessária para o êxito da reestruturação do auto-conceito, já que a imagem corporal e o auto-conceito representam a consciência da própria individualidade.

Pode-se observar, até aqui, que uma gama enorme de sentimentos confusos e dolorosos podem acompanhar a pessoa a partir do aparecimento da doença e ser agravada com a internação hospitalar.

Dividimos didaticamente o acompanhamento psicológico ao paciente cirúrgico em três momentos específicos: o pré-operatório, o trans-operatório e o pós-operatório. Este último, subdividido em duas fases: imediato e tardio. Cada um desses momentos é representado por movimentos emocionais, que estão intimamente ligados às experiências e expectativas vivenciadas pelo paciente, mas, particularmente, são marcados pela forma com que a pessoa elabora essas vivências. $\mathrm{O}$ pré-operatório é vivenciado a partir do tipo de cirurgia a ser realizada, mas também pela forma com que o paciente elabora a situação vivida. Certo medo e ansiedade são reações consideradas normais. Porém, na medida em que essas condições se elevam e se somam à tensão, estresse ou outras condições adversas do estado emocional, o paciente sofre interferências em seu organismo que podem prejudicar o processo cirúrgico.

A efetivação de um bom acompanhamento psicológico no pré-operatório tem influência direta nas reações do paciente no trans e pós-operatório, já que existem relações entre o estado emocional do paciente nessa três fases da cirurgia.

Tensão e ansiedade no pré-operatório = a maior risco de depressão, baixa aderência ao programa de reabilitação e outras intercorrências no pós-operatório.

Durante o trans-operatório, até alguns anos atrás, acreditava-se que o fato de o paciente estar em coma anestésico (nos casos cirúrgicos onde foi usada anestesia geral) criava uma condição de bloqueio das interferências psicológicas sobre o estado do paciente. Como descrevemos acima, esse fato parece não ser tão absoluto assim. No entanto, o mais surpreendente, particularmente para os anestesistas, foram constatações apresentadas por pesquisas realizadas psicólogo norte-americano H. Benett ${ }^{20}$, da Universidade da Califórnia, apresentadas em 1989, por ocasião do Congresso Internacional de Anestesiologia nos EUA. O autor provou que boa parte dos pacientes em coma anestésico não fica totalmente inconsciente e, portanto, incapaz de receber e interpretar estímulos vindos de fora, mas encontrava-se num 
estado de consciência alterada e que, pelas pesquisas, mostrava-se muito mais sugestionável aos estímulos que recebia, e que reagia a estes. Fica, então, um ponto importante a ser considerado pelas equipes de cirurgia: palavras, frases, conversas, discussões etc., ocorridas dentro do Centro Cirúrgico, podem influenciar tanto positiva como negativamente o paciente em seus comportamentos no pós-operatório. Conforme assinalamos anteriormente, costuma-se dividir o pós-operatório em dois tempos: o pós-operatório imediato e o tardio.

Psicologicamente, um depende muito do outro no que tange a sua evolução. É no pós-operatório imediato que o paciente irá, voltando da anestesia, gradativamente reencontrar-se com a vida e consigo mesmo, uma vez superado o evento crítico (cirurgia). Quanto maior o stress e tensão vividos pela pessoa, maiores as dificuldades em enfrentar, superar ou administrar os limites que a cirurgia lhe impôs.

A presença do Psicólogo na equipe que tratará da reabilitação do paciente é de fundamental importância, pois todas as elaborações, fantasias, medos, depressão (eventualmente) podem ser detectadas e trabalhadas junto a este de forma a não se tornarem empecilhos para sua reintegração à vida.

Em linhas gerais, esses três momentos, como vimos, são carregados de emoções e reações psicológicas e comportamentais que podem interferir direta ou indiretamente no curso da patologia e da própria cirurgia. As experiências oriundas da internação, dos sentimentos de invasão e agressão, as distorções de compreensão e participação tanto do paciente quanto de sua família no processo cirúrgico são aspectos mais do que significativos para fundamentar e comprovar a necessidade do Psicólogo na equipe interdisciplinar do Hospital. Longe de se propor o esgotamento do tema neste artigo, procurou-se abordar alguns aspectos que servissem como ponto de partida para inúmeras discussões. A evolução da especialidade Psicologia Hospitalar já se dedica a estudos sistematizados e ao desenvolvimento de técnicas específicas de intervenção nas distintas modalidades cirúrgicas, considerando suas peculiaridades e os inúmeros fatores que diferenciam não só os protocolos e procedimentos, mas os impactos que estas trazem aos pacientes. Cabe, agora, não só às instituições e demais profissionais da área de saúde possibilitarem a introdução deste profissional nas equipes, mas, sobretudo, ao próprio Psicólogo instrumentalizar-se adequadamente para conquistar, pelo seu conhecimento, pelo valor de seu trabalho e pela sua dedicação, seu espaço dentro das equipes cirúrgicas.

\section{Referências}

1. Werthmeier M, Pequena História da Psicologia. São Paulo: Ed. da Universidade de S. Paulo; 1972.

2. Foucault M, O nascimento da clínica.Rio de Janeiro: Ed. Graal Ltda; 1984.
3. Eakstermann AJ. O Clínico como Psicanalista. Rev. Contribuições Psicanalíticas à Medicina Psicossomática. 1977; Vol. I.

4. Barra EA, Psicología de la Salud. Concepción, Chile: Universidad de Concepción, Proyecto de Desarrollo de la Docencia; 2000. p.7.

5. Mendes EV. A evolução da prática médica. Belo Horizonte: Ed. Fumarc; 1985.

6. Westphal MF, Santos JLF. Práticas emergentes de um novo paradigma de saúde: o papel da universidade. Estudos Avançados 1999; 13 (35).

7. Ministério da Saúde (Brasil). Por que um Programa de Humanização nos Hospitais. Brasília: Comitê Técnico do Programa Nacional de Humanização da Assistência Hospitalar; 2000.

8. Paiva LM. Medicina Psicossomática. 2nd ed. São Paulo: Ed. Artes Médicas; 1994.

9. Mello Fo. J. Psicossomática Hoje. Porto Alegre: Artes Médicas; 1992.

10. Forattini OP. Ecologia Epidemiologia e Sociedade. S. Paulo: Ed. Artes Médicas; 1992.

11. Lalonde M. O conceito de 'campo da saúde' uma perspectiva canadense. Organização Panamericana da Saúde 1996: Washington. D.C.; Publicação científica: 577.

12. Terris M. Conceptos de la promoción de la salud: dualidades de la teoría de la salud publica. In: OPAS / OMS 1996; Promoción de la salud: una antología: Washington.

13. Ministério da Saúde (Brasil). Promoção da Saúde: Brasília (DF); 2000.

14. Brandão CLC. Relação Médico Paciente Estratégias de Atuação Psicológica no Hospital do Servidor Público Municipal de São Paulo. São Paulo: Monografia de Especialização em Psicologia Hospitalar: Nêmeton Centro de Estudos e Pesquisas em Psicologia e Saúde; 2004.

15. Cortese VMC. A Correlação da Imagem do Cirurgião para o Paciente e deste para o Cirurgião no Contexto de Internação Hospitalar. São Paulo: Monografia de Especialização em Psicologia Hospitalar: Nêmeton Centro de Estudos e Pesquisas em Psicologia e Saúde; 2004.

16. Mello JB, Moraes IN, Nahas. Residente de Cirurgia. São Paulo: Ed. Rocca; 1992.

17. Grau JA. Historia de la Psicología de la Salud. In: Memorias del V Congreso Iberoamericano de Psicología de la Salud. American Behavior Association - ABA Colombia; 2000 nov; Cartagena, Colombia; 2000.

18. Sebastiani RW. Histórico e Evolução da Psicologia da Saúde numa Perspectiva Latino-americana. In: Camon VAA editor. Psicologia da Saúde: um novo significado para a prática clínica. São Paulo: Thomson Learning; 2000. p. 201-222.

19. Maia EMC, Sebastiani RW. Psicologia de la Salud em Brasil: 50 años de historia. Suma Psicológica 2003 Mar 10; 1: 25-42.

20. Benett H. Psychological response in anesthesic cases. Journal of American Anesthesiology Association 1989 Sept.; E.U.A. 